\title{
Clinical Characteristics of Coronavirus Disease 2019 (COVID-19): A Comparison Between Laboratory-Confirmed and Clinically Suspected Patients
}

\author{
Qi Li ${ }^{1,2}$ (D) Meng-ting Jiang ${ }^{3} \cdot$ Su-e Yuan $^{1,2}$ (D)
}

Received: 24 December 2020 / Accepted: 2 November 2021 / Published online: 15 November 2021

(c) Shiraz University 2021

\begin{abstract}
To investigate the characteristic findings between laboratory-confirmed and clinically suspected patients with COVID-19. In this retrospective study, we included patients admitted to the Xiangya Hospital from Jan 24 to Feb 10, 2020. Two researchers separately collected and sorted out the patients' epidemiological, demographic, clinical, laboratory, and radiologic findings. SPSS was performed to analyze the collected data. 241 patients were admitted, including 28 (45.5; IQR, 34.0-52.5) confirmed and 213 (42.0; IQR, 30.0-57.0) suspected patients. The prevalence of COVID-19 disease in males was significantly higher than in females $(64.3 \%$ vs. $35.7 \%, P=0.033)$. Before admission of the confirmed and suspected undiagnosed cases, the onset of symptoms is often manifested as respiratory symptoms such as fever $(35.7 \%$ vs. $27.7 \%)$ and cough $(30.7 \%$ vs. $32.1 \%)$. Twenty patients $(71.4 \%)$ had an exposure history to high-risk areas, and 14 patients $(50.0 \%)$ traveled or lived in a high-risk area in the confirmed group, which was significantly different from the suspected group. The pulmonary imaging of the patients in the confirmed group was primarily manifested as ground-glass opacity (89.3\%). A total of 499 nucleic acid testing (NAT) was performed to determine the 28 COVID-19 positive throat swabs among the 241 patients. Whether there is a history of high-risk area exposure in the epidemiological investigation is essential in distinguishing the suspected patients from the confirmed patients. Multiple nucleic acid tests were used as the basis for the diagnosis of COVID-19, and during CT examination, ground-glass opacity was used as a COVID-19 indicator.

Trail registration Trail registration number. 202012195, Date of registration: 2020.12.22 "retrospectively registered".
\end{abstract}

Keywords COVID-19 · Coronavirus infections · Pneumonia $\cdot$ Suspected cases

Su-e Yuan

1dyse2018@csu.edu.cn

Qi Li

1229438742@qq.com

Meng-ting Jiang

xyhljmt@csu.edu.cn

1 Teaching and Research Section of Clinical Nursing, Xiangya Hospital of Central South University, No. 87 Xiangya Road, Changsha 410008, Hunan, China

2 Xiangya Nursing School, Central South University, No. 172 Tongzipo Road, Changsha 410013, Hunan, China

3 Department of Infectious Disease, Xiangya Hospital, Central South University, Changsha, China

\section{Introduction}

Idiopathic pneumonia caused by severe acute respiratory syndrome coronavirus 2 (SARS-CoV-2), has spread globally since its outbreak in December 2019 (WHO 2020a, b, c). World Health Organization (WHO) declared the novel coronavirus outbreak a Public Health Emergency of International Concern globally on January 30, 2020, announcing a name for the new coronavirus disease: COVID-19 on February 11, 2020. COVID-19 escalated it to a global pandemic on March 11, 2020 (WHO 2020a, b, c). As of November 2, 2020, there have been more than 46,166,182 individuals in more than 200 countries with cumulative confirmed COVID-19, of which more than 1,196,362 have died (WHO 2020a, b, c). In China, there have been more than 91,955 cumulative confirmed 
cases of COVID-19, of which more than 4,746 have died (NHC 2020).

Real-time RT-PCR (reverse transcription-polymerase chain reaction) detection is an important laboratory method for diagnosing COVID-19 (Corman et al. 2020; Pang et al. 2020). However, the missed diagnosis of nucleic acid tests leads to an underestimation of patients with COVID-19. For example, many studies have shown that the hospitalized patients tested positive for the diagnosis of COVID-19 after testing negative multiple times (Huang et al. 2020; Li et al. 2020b, c, d, e, a; Long et al. 2020), which may be related to improper sample collection and low viral load of the patients (Yan et al. 2020; Li et al. 2020b, c, d, e, a). Moreover, the issue of stability of nucleic acid testing also prompts the possibility of missed diagnosis and more potentially infected people with COVID-19. Evidence shows the possibility of person-to-person transmission ( $\mathrm{Li}$ et al. 2020b, c, d, e, a), as well as the droplets from face-toface contact, are the most common form of transmission during conversation, coughing, or sneezing (Wiersinga et al. 2020). Therefore, it is of great significance for us to learn more about the clinical characteristics of COVID-19 confirmed and suspected patients in order to increase selfprotection and prevent infection.

The most important prevention measures of the Chinese government during this epidemic include pairing assistance and closed management, such as city lockdown (Li et al. 2020b, c, d, e, a). The number of confirmed and imported cases has been increasing recently from many regions within China (NHC 2020). The Chinese government closely monitored, analyzed, and swiftly responded to the transferred confirmed patients of COVID-19 through fever clinics or preliminary screening institutions to infectious disease specialized hospitals for further treatment.

Given that the ongoing pandemic poses a significant challenge to human beings, we retrospectively collected the data of patients who had been admitted to the hospital from Jan 24 to Feb 10, 2020, in order to provide a scientific basis for early diagnosis, the analysis of the clinical characteristics of laboratory-confirmed and clinically suspected patients, as well as providing a scientific basis for the identification of the early diagnosis and the reduction of missed cases.

\section{Patients and Methods}

\subsection{Design and Data Source}

This single-center retrospective study analyzed the clinical characteristics of people suspected of COVID-19 infection from one tertiary hospital in Changsha, China. The Ethics Committee of the review board of the Xiangya Hospital of the Central South University approved this study (No. 202012195).

\subsection{Study Population and Data collection}

People with a primary diagnosis of suspected COVID-19, defined by Guidelines on the Novel Coronavirus-Infected Pneumonia Diagnosis and Treatment (NHC 2020), from Jan 24 to Feb 10, 2020, from the Xiangya Hospital were included. Patients with at least one medical record of a positive COVID-19 result verified with a nucleic acid test were classified into the confirmed group, and patients who were not COVID-19 positive via a swab test were classified into suspected groups, even though they had clinical symptoms similar to COVID-19. Patients' data including epidemiological contact history with COVID-19 patients or were in high-risk-area, clinical symptoms, demographic information, personal health history, laboratory, and radiologic findings were extracted. Two trained researchers (LQ and JMT) separately collected and sorted out the data to ensure its integrity.

\subsection{Statistical Analysis}

Statistical analysis was performed using SPSS software version 18.0. Descriptive statistics were used to summarize the data; results are presented as median (interquartile range, IQR) for continuous variables and numbers (\%) for categorical variables. The inter between-group comparison was performed using an independent student's t-tests or a Mann-Whitney test for continuous variables and $\chi 2$ test or Fisher's exact test for categorical variables, as appropriate. A two-sided P-value of less than 0.05 was considered statistically significant.

\section{Results}

\subsection{Demographic and Clinical Characteristics}

Of the 241 patients identified, 28 were confirmed with positive COVID-19 nucleic acid test results (11.6\%). In this sample, the prevalence of positive swabs in males was significantly higher than in females $(64.3 \%$ vs. $35.7 \%$, $P=0.033)$. As shown in Table 1 , the median age of laboratory-confirmed patients was 45.5 (IQR, 34.0-52.5), and over forty-four percent of them were in the 18-44 age group.

Of the total patients, 218 patients $(90.5 \%)$ including 25 confirmed cases and 193 suspected COVID-19 cases, went to the fever clinic upon their first departmental visit. A statistical difference was observed in the exposure history to high-risk areas between the two groups 
Table 1 Demographic data and baseline clinical characteristics of COVID-19 suspected and confirmed patients

\begin{tabular}{|c|c|c|c|c|}
\hline Characteristics & $\begin{array}{l}\text { Total patients } \\
(\mathrm{n}=241)\end{array}$ & $\begin{array}{l}\text { Confirmed patients } \\
(\mathrm{n}=28)\end{array}$ & $\begin{array}{l}\text { Suspected patients } \\
(\mathrm{n}=213)\end{array}$ & P-value \\
\hline Age (years)-no, $(\%)$ & & & & 0.536 \\
\hline Median (IQR) & $42.0(30.5-57.0)$ & $45.5(34.0-52.5)$ & $42.0(30.0-57.0)$ & \\
\hline$<18$ & $19(7.9)$ & $1(3.6)$ & $18(8.5)$ & \\
\hline $18-44$ & $106(44.0)$ & $12(42.9)$ & $94(44.1)$ & \\
\hline $45-59$ & $71(29.5)$ & $12(42.9)$ & $59(27.7)$ & \\
\hline $60-74$ & $35(14.5)$ & $2(7.1)$ & $33(15.5)$ & \\
\hline $75-89$ & $9(3.7)$ & $1(3.6)$ & $8(3.8)$ & \\
\hline$\geq 90$ & $1(0.4)$ & $0(0.0)$ & $1(0.5)$ & \\
\hline Gender-no, $(\%)$ & & & & $0.033 *$ \\
\hline Male & $117(48.5)$ & $18(64.3)$ & $99(46.5)$ & \\
\hline Female & $124(51.5)$ & $10(35.7)$ & $114(53.5)$ & \\
\hline First visit department-no $(\%)$ & & & & 0.454 \\
\hline Fever clinic & $218(90.5)$ & $25(89.3)$ & $193(90.6)$ & \\
\hline Medical department & $4(1.7)$ & $1(3.6)$ & $3(1.4)$ & \\
\hline Surgical department & $14(5.8)$ & $1(3.6)$ & $13(6.1)$ & \\
\hline Emergency department & $3(1.2)$ & $1(3.6)$ & $2(0.9)$ & \\
\hline Obstetrics department & $1(0.4)$ & $0(0.0)$ & $1(0.5)$ & \\
\hline Outpatient department & $1(0.4)$ & $0(0.0)$ & $1(0.5)$ & \\
\hline Exposure history to HRA-no $(\%)$ & & & & $0.000 *$ \\
\hline Yes & $87(36.1)$ & $20(71.4)$ & $67(31.5)$ & \\
\hline No & $146(60.6)$ & $7(25.0)$ & $139(65.3)$ & \\
\hline Unclear & $8(3.3)$ & $1(3.6)$ & $7(3.3)$ & \\
\hline Route of exposure-no (\%) & & & & $0.000 *$ \\
\hline History of HRA sojourn & $48(19.9)$ & $14(50.0)$ & $34(16.0)$ & \\
\hline Contacting with HRA person & $44(18.3)$ & $6(21.4)$ & $38(17.8)$ & \\
\hline Contacting with confirmed case & $43(17.8)$ & $3(10.7)$ & $40(18.8)$ & \\
\hline Unclear & $88(36.5)$ & $2(7.1)$ & $86(40.4)$ & \\
\hline No & $18(7.5)$ & $3(10.7)$ & $15(7.0)$ & \\
\hline \multicolumn{5}{|l|}{ Incubation period (days) } \\
\hline \multirow[t]{2}{*}{ Median (IQR) } & $114 / 241$ & $18 / 28$ & $96 / 213$ & \\
\hline & $10.50(7.0-16.25)$ & $8.5(5.75-12.5)$ & $11.0(7.0-17.0)$ & \\
\hline Incipient symptom before admission-no $(\%)$ & & & & 0.874 \\
\hline Fever & 69 (28.6) & $10(35.7)$ & $59(27.7)$ & \\
\hline Cough & $74(30.7)$ & $9(32.1)$ & $65(30.5)$ & \\
\hline Fever and cough & $17(7.1)$ & $1(3.6)$ & $16(7.5)$ & \\
\hline Asymptomatic & $18(7.5)$ & $1(3.6)$ & $17(8.0)$ & \\
\hline Others & $63(26.1)$ & $7(25.0)$ & $56(26.3)$ & \\
\hline \multicolumn{5}{|l|}{ Fever on admission (days) - no (\%) } \\
\hline \multirow[t]{2}{*}{ Median (IQR) } & $123 / 241$ & $18 / 28$ & $105 / 213$ & \\
\hline & $2(1-5)$ & $2(1-7)$ & $2(1-5)$ & \\
\hline Median highest temperature-no $(\%)$ & & & & 0.102 \\
\hline Median (IQR) & $37.8(36.7-38.5)$ & $37.9(37.7-38.1)$ & $37.8(36.5-38.6)$ & \\
\hline$<37.3$ & $51 / 174(29.3)$ & $2 / 19(10.5)$ & $49 / 155(31.6)$ & \\
\hline $37.3-38.0$ & $55 / 174(31.6)$ & $10 / 19(52.6)$ & $45 / 155(29.0)$ & \\
\hline $38.1-39.0$ & $50 / 174(28.7)$ & $6 / 19(31.6)$ & $44 / 155(28.4)$ & \\
\hline$>39.0$ & $17 / 174(10.3)$ & $1 / 19(5.3)$ & $17 / 155(11.0)$ & \\
\hline \multicolumn{5}{|l|}{ Other symptoms-no, $(\%)$} \\
\hline Fatigue & $47(19.5)$ & $9(32.1)$ & $38(17.8)$ & 0.051 \\
\hline
\end{tabular}


Table 1 (continued)

\begin{tabular}{|c|c|c|c|c|}
\hline Characteristics & $\begin{array}{l}\text { Total patients } \\
(\mathrm{n}=241)\end{array}$ & $\begin{array}{l}\text { Confirmed patients } \\
(\mathrm{n}=28)\end{array}$ & $\begin{array}{l}\text { Suspected patients } \\
(\mathrm{n}=213)\end{array}$ & P-value \\
\hline Cough & $116(48.1)$ & $15(53.6)$ & $101(47.4)$ & 0.475 \\
\hline Expectoration & $47(20.3)$ & $6(21.4)$ & $41(19.2)$ & 0.772 \\
\hline Yellow phlegm & $16(34.0)$ & $2 / 6(33.3)$ & $14 / 41(34.1)$ & \\
\hline White phlegm & $9(19.1)$ & $3 / 6(50.0)$ & 6/41 (14.6) & \\
\hline White thin sputum & $3(6.4)$ & $1 / 6(16.7)$ & $2 / 41(4.9)$ & \\
\hline Bloody sputum & $4(8.5)$ & $0 / 6(0.0)$ & 4/41 (9.8) & \\
\hline Others & $15(31.9)$ & $0 / 6(0.0)$ & 15/41 (36.6) & \\
\hline Chills & $57(23.7)$ & $6(21.4)$ & $51(23.9)$ & 0.768 \\
\hline Shiver & $14(5.8)$ & $2(7.1)$ & $12(5.6)$ & 0.670 \\
\hline Nausea or vomiting & $8(3.3)$ & $1(3.6)$ & $7(3.3)$ & 1.000 \\
\hline Muscular soreness & $12(5.0)$ & $2(7.1)$ & $10(4.7)$ & 0.636 \\
\hline Chest pain & $1(0.4)$ & $0(0.0)$ & $1(0.5)$ & 1.000 \\
\hline Sore throat & $18(75)$ & $0(0.0)$ & $18(8.5)$ & 0.240 \\
\hline Running nose & 28 (11.6) & $2(7.1)$ & $26(12.2)$ & 0.752 \\
\hline Dyspnea & $15(6.2)$ & $0(0.0)$ & $15(7.0)$ & 0.228 \\
\hline Vital signs-no $(\%)$ & & & & 0.527 \\
\hline Normal & $179(74.3)$ & $23(82.1)$ & $156(73.2)$ & \\
\hline Fast pulse (times per minute) & 28 (11.6) & $1(3.6)$ & $27(12.6)$ & \\
\hline $100-120$ & $16(6.6)$ & $0(0.0)$ & $16(7.5)$ & \\
\hline $121-150$ & $10(4.1)$ & $1(3.6)$ & $9(4.2)$ & \\
\hline$>150$ & $2(0.83)$ & $0(0.0)$ & $2(0.9)$ & \\
\hline Blood pressure (mmHg) & $38(15.8)$ & $4(14.3)$ & $30(14.1)$ & \\
\hline Hypotension (systolic pressure $<90$ ) & $3(1.2)$ & $0(0.0)$ & $3(1.4)$ & \\
\hline Hypertension level 1 & $24(10.0)$ & $4(14.3)$ & $20(9.4)$ & \\
\hline Hypertension level 2 & $7(3.0)$ & $0(0.0)$ & $7(3.3)$ & \\
\hline Hypertension level 3 & $0(0.0)$ & $0(0.0)$ & $0(0.0)$ & \\
\hline Previous history-no (\%) & & & & 0.140 \\
\hline No & $141(58.5)$ & $20(71.4)$ & $121(56.8)$ & \\
\hline Yes & $100(41.5)$ & $8(28.6)$ & $92(43.2)$ & \\
\hline \multicolumn{5}{|l|}{ Coexisting disorder-no $(\%)$} \\
\hline Hypertension & $22(9.1)$ & $2(7.1)$ & $20(9.4)$ & 1.000 \\
\hline Diabetes & $15(6.2)$ & $2(7.1)$ & $13(6.1)$ & 0.688 \\
\hline Cardiovascular disease & $7(2.9)$ & $0(0.0)$ & $7(3.3)$ & 1.000 \\
\hline Neurological disease & $5(2.1)$ & $0(0.0)$ & $5(2.3)$ & 1.000 \\
\hline Cancer & $7(2.9)$ & $0(0.0)$ & $7(3.3)$ & 1.000 \\
\hline Pulmonary disease & $11(4.6)$ & $2(7.1)$ & $9(4.2)$ & 0.622 \\
\hline Hepatitis & $9(3.7)$ & $1(3.6)$ & $8(3.8)$ & 1.000 \\
\hline Chronic renal disease & $6(2.5)$ & $0(0.0)$ & $6(2.8)$ & 1.000 \\
\hline Immune diseases & $8(3.3)$ & $0(0.0)$ & $8(3.8)$ & 0.601 \\
\hline
\end{tabular}

${ }^{*} P<0.05$

Hypertension level 1: (Mild) systolic pressure140-159 $\mathrm{mmHg}$ or diastolic pressure 90-99 $\mathrm{mmHg}$ Hypertension level 2: (Moderate) systolic pressure $160-179 \mathrm{mmHg}$ or diastolic pressure $100-109 \mathrm{mmHg}$ Hypertension level 3: (Sever)systolic pressure $\geq 180 \mathrm{mmHg}$ or diastolic pressure $\geq 110 \mathrm{mmHg}$ HRA: high-risk area 
$(P<0.001)$. There were 23 patients $(82.1 \%)$ in the confirmed group having epidemiological contact history compared to $112(52.6 \%)$ in the suspected group.

The most common symptoms before admission were both fever and cough within the two groups. Other symptoms including fatigue, expectoration, chills, nausea or vomiting, muscular soreness, chest pain, sore throat, running nose, and dyspnea were also prevalent; however, there were no statistical differences between the two groups. In terms of abnormal vital signs, the primary abnormalities present were fast pulse $(3.6 \%$ vs. $12.6 \%)$, hypotension $(0.0 \%$ vs. $1.4 \%)$, and hypertension $(14.3 \%$ vs. $12.7 \%$ ) in the confirmed and clinically suspected group (Table 1).

\subsection{Laboratory and Radiologic Findings}

Table 2 shows the laboratory and radiologic findings. In the suspected group, 6 patients were tested positive for influenza $A$ and 2 patients for influenza B. Moreover, the prevalence of patients with ground-glass opacity changes and local patchy shadowing within CT chest scans in the confirmed group was higher than that in the suspected group $(89.3 \%$ vs. $40.1 \% ; 14.3 \%$ vs. $2.2 \%)$. Based on the available complete data in the confirmed group, the time from the latest exposure time to the CT finding of groundglass opacity was 0.5-15 days; the average time was approximately 7 days (Fig. 1). Table 2 shows that hemoglobin count primarily concentrates in the range of less than $100 \times 10^{9} \mathrm{~g} / \mathrm{L}$ in both groups $(80.0 \%$ vs. $85.2 \%)$.

Table 2 Laboratory and radiologic findings of COVID-19 suspected and confirmed patients with different outcomes

\begin{tabular}{|c|c|c|c|c|}
\hline Characteristics & $\begin{array}{l}\text { Total patients } \\
(\mathrm{n}=241)\end{array}$ & $\begin{array}{l}\text { Confirmed patients } \\
(\mathrm{n}=28)\end{array}$ & $\begin{array}{l}\text { Suspected patients } \\
(\mathrm{n}=213)\end{array}$ & P-value \\
\hline Influenza-no (\%) & & & & 0.372 \\
\hline A & $6(2.5)$ & $0(0.0)$ & $6(2.8)$ & \\
\hline B & $2(0.8)$ & $0(0.0)$ & $2(0.9)$ & \\
\hline No & $213(88.4)$ & $28(100)$ & $185(86.9)$ & \\
\hline Unclear & $20(8.3)$ & $0(0.0)$ & $20(9.4)$ & \\
\hline Chest CT finding-no $(\%)$ & & & & $0.000 *$ \\
\hline Ground-glass opacity & $111(46.1)$ & $25(89.3)$ & $86(40.1)$ & \\
\hline Local patchy shadowing & $30(12.4)$ & $4(14.3)$ & $26(2.2)$ & \\
\hline Bilateral patchy shadowing & $33(13.7)$ & $10(35.7)$ & $23(10.8)$ & \\
\hline Inflammatory and infectious change & $51(21.2)$ & $3(10.7)$ & $48(22.5)$ & \\
\hline Interstitial abnormality & $3(1.2)$ & $0(0.0)$ & $3(1.4)$ & \\
\hline Others & $80(33.2)$ & $3(10.7)$ & $77(36.2)$ & \\
\hline Hemoglobin count $\left(\times 10^{9} \mathrm{~g} / \mathrm{L}\right)-$ no $(\%)$ & & & & 0.552 \\
\hline$<100$ & 29/187 (15.5) & $5 / 25(20.0)$ & $24 / 162(14.8)$ & \\
\hline$\geq 100$ & $158 / 187(84.5)$ & $20 / 25(80.0)$ & $138 / 162(85.2)$ & \\
\hline \multicolumn{5}{|l|}{ White blood cell count $\left(\times 10^{9} \mathrm{~g} / \mathrm{L}\right)$ no $(\%)$} \\
\hline$<4$ & $3 / 186(1.6)$ & $0 / 25(0.0)$ & $3 / 161(1.9)$ & $0.005 *$ \\
\hline $4-10$ & $68 / 186(36.6)$ & $17 / 25(76.5)$ & $51 / 161(31.7)$ & \\
\hline$>10$ & $115 / 186(61.8)$ & $8 / 25(32.0)$ & $107 / 161(66.5)$ & \\
\hline Neutrophil count $\left(\times 10^{9} \mathrm{~g} / \mathrm{L}\right)-$ no $(\%)$ & & & & $0.002 *$ \\
\hline$<1.8$ & $13 / 180(7.2)$ & $4 / 23(17.4)$ & $9 / 157(5.7)$ & \\
\hline $1.8-6.3$ & $102 / 180(56.7)$ & $17 / 23(73.9)$ & $85 / 157(54.1)$ & \\
\hline$>6.3$ & $65 / 180(36.1)$ & $2 / 23(8.7)$ & $63 / 157(40.1)$ & \\
\hline Lymphocyte count $\left(\times 10^{9} \mathrm{~g} / \mathrm{L}\right)-$ no $(\%)$ & & & & 1.000 \\
\hline$<1.0$ & $130 / 166(78.3)$ & $17 / 21(81.0)$ & $113 / 145(77.9)$ & \\
\hline$\geq 1.0$ & $36 / 166(21.7)$ & $4 / 21(19.0)$ & $32 / 145(22.1)$ & \\
\hline Monocytes count $\left(\times 10^{9} \mathrm{~g} / \mathrm{L}\right)-$ no $(\%)$ & & & & 0.744 \\
\hline$<1.0$ & $156 / 180(86.7)$ & $21 / 23(91.3)$ & 135/157 (86.0) & \\
\hline$\geq 1.0$ & 24/180 (13.3) & $2 / 23(8.7)$ & $22 / 157$ (14.0) & \\
\hline
\end{tabular}

${ }^{*} P<0.05$ 


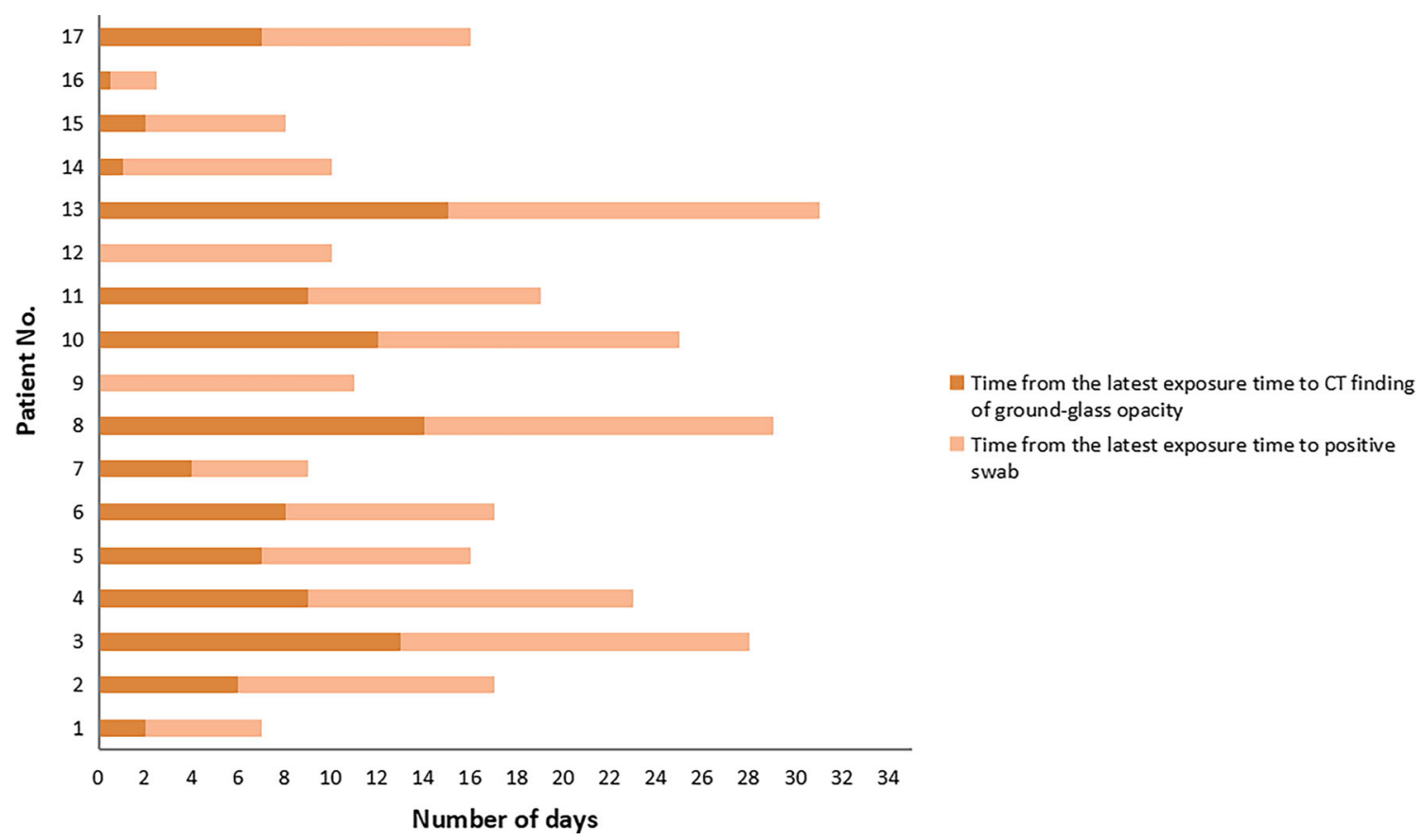

Fig. 1 Time interval from the last exposure to ground-glass opacity CT imaging and positive swab test (days)

Laboratory findings where significant differences have been found include white blood cell count $\left(P=0.005^{*}\right)$ and neutrophil count $(P=0.002 *)$.

\subsection{Nucleic Acid Test and Clinical Outcomes}

A total of 499 NATs were performed in this health care setting in order to determine the status of COVID-19 among these 241patients. Finally, $22(78.6 \%)$ cases tested positive for the first time in all confirmed cases, 4 (14.3\%) tested positive for a second time, and 2 of them tested positive after a third NAT. One case failed to find a positive swab after 8 NAT in 213 clinically suspected cases. The details of the NAT information of the 28 confirmed cases are shown in Fig. 2. In this study, 17 patients reported the last time of possible COVID-19 exposure. Figure 1 shows the length from the last time of possible COVID-19 exposure to the patients obtaining a positive swab test was $2-16$ days, and the average was approximately 10 days. In this sample, 28 COVID-19 patients successfully survived and were transferred to a local specified hospital for COVID-19 treatment; Table 3 shows the clinical outcomes of these patients.

\section{Discussion}

This is a retrospective study on the clinical characteristics and the laboratory and radiology findings of all patients who had a primary diagnosis of suspected COVID-19 from
Jan 24, 2020, to Feb 10, 2020. We descriptively analyzed and presented the characteristics of the laboratory-confirmed and the clinically suspected patients, providing evidence for clinical practice and clinical facility decisionmaking.

Our findings are in accordance with previous studies showing that most COVID-19 male patients are more likely to be infected with this virus (Zhou et al. 2020; Chen et al. 2020; Li et al. 2002). Zhou et al. (2020) study showed that male patients outnumbered female patients in the group of non-survivor (70\% vs 30\%). Chen et al.'s (2020) study also demonstrated that the male sex was in the majority whether in the death group (73\% vs $27 \%$ ) or the recovery group (55\% vs $45 \%)$. Furthermore, $\mathrm{Li}$ et al. (2020b, c, d, e, a) concluded that males accounted for a higher proportion of hospitalized patients $(76.9 \%$ vs $23.1 \%)$ as well as health care staff $(83.3 \%$ vs $16.7 \%)$. Based on the previous studies, several factors could explain the gender difference: females tend to have lower levels of inflammatory mediators, higher levels of estrogen and lower levels of testosterone, and higher levels of immune responses than males (Gebhard et al. 2020; Kopel et al. 2020). However, whether it is related to gender remains to be proven.

One finding was the extent to which the body temperature of $52.6 \%$ of the confirmed patients was primarily concentrated in the range of $37.3-38.0^{\circ} \mathrm{C}$. This finding may be related to the fact that all of the confirmed patients are of the common type defined by the diagnosis and treatment scheme for SARS- CoV-2 of Chinese (eighth 


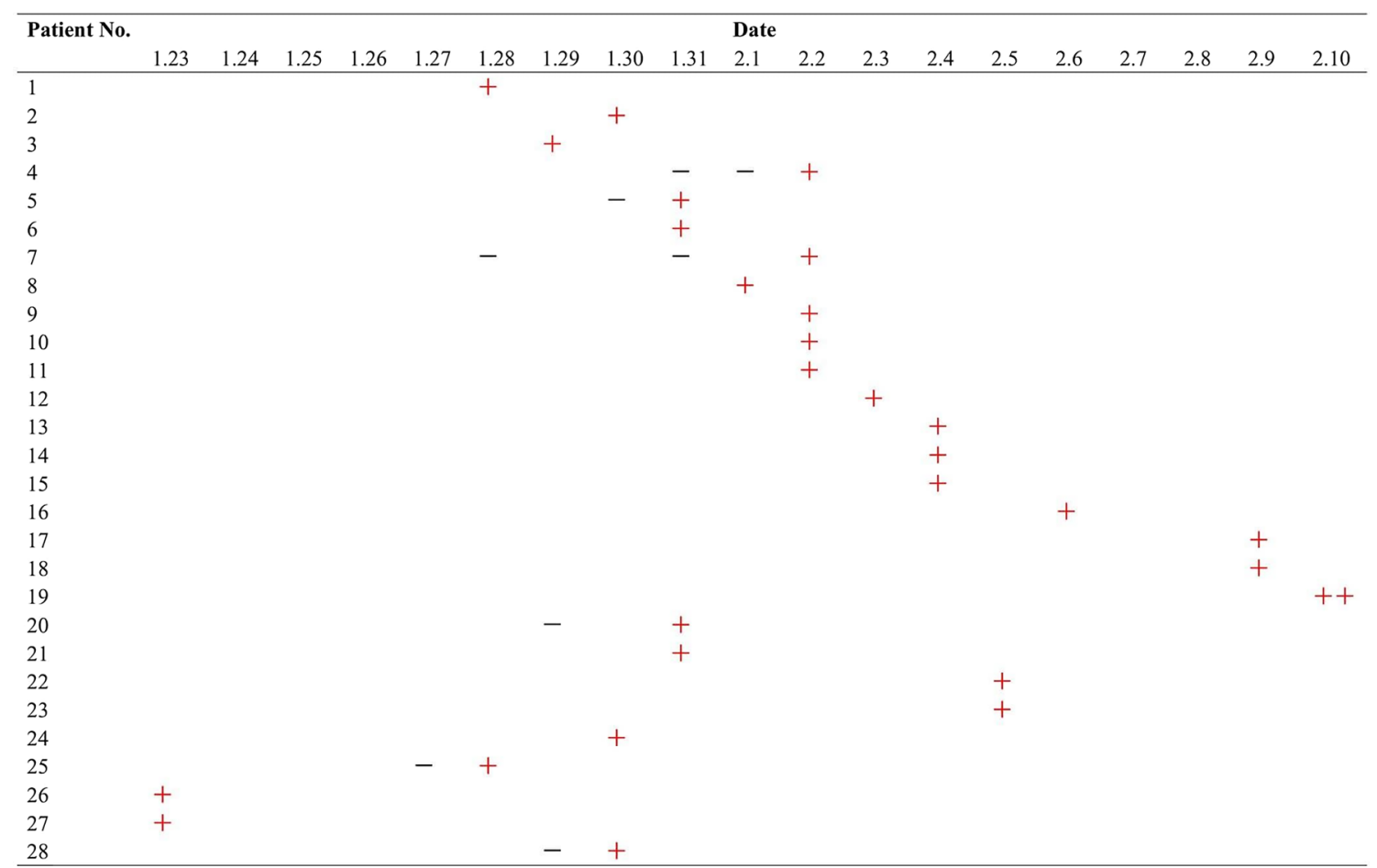

Fig. 2 Nucleic acid test of COVID-19 confirmed patients. " + ", positive; “ - ", negative

Table 3 Clinical outcomes of COVID-19 confirmed and suspected patients

\begin{tabular}{llll}
\hline Characteristics & $\begin{array}{l}\text { Total patients } \\
(\mathrm{n}=241)\end{array}$ & $\begin{array}{l}\text { Confirmed patients } \\
(\mathrm{n}=28)\end{array}$ & $\begin{array}{l}\text { Suspected patients } \\
(\mathrm{n}=213)\end{array}$ \\
\hline $\begin{array}{l}\text { Clinical outcomes-no (\%) } \\
\text { Discharge from isolation }\end{array}$ & $172(71.4)$ & $0(0.0)$ & $172(80.8)$ \\
Transfer to another department & $35(14.5)$ & $0(0.0)$ & $35(16.4)$ \\
Transfer to another hospital & $28(11.6)$ & $28(89.5)$ & $0(0.0)$ \\
Death & $3(1.2)$ & $0(0.0)$ & $3(1.4)$ \\
\hline
\end{tabular}

edition) (NHC 2020). Another possible explanation is that the white blood cell count was in the normal range in $76 \%$ of confirmed patients. Our study also found that the average and longest time from the last time of viral exposure to positive swab test were 10 and 16 days, respectively, suggesting that if there are no positive results after 16 days from the last exposure time, the COVID-19 infection rate is extremely low.

The most apparent CT chest finding to emerge from the analysis is that ground-glass opacity was the most characteristic radiographic feature for those patients with COVID-19 in the early days of the outbreak within this study. Although CT is not the "gold standard" for COVID19 diagnosis, it is still an important auxiliary imaging examination. The previous study also classified the role of a chest CT in the diagnostic performance of COVID-19 (Himoto et al. 2020) and further confirmed that CT imaging has a high sensitivity for the diagnosis of COVID-19 (Ai et al. 2020). The most clinically relevant finding is that the average and longest time from the last time of viral exposure to the CT finding of ground-glass opacity was 7 and 15 days, respectively. From the findings, it can be suggested that a chest CT 15 days after exposure to the virus needs to be repeated to verify a potential COVID-19 infection. However, the chest CT has its limitation. In this study, up to $40.1 \%$ of clinically suspected patients showed ground-glass opacity changes. This may be because the CT findings (e.g., ground-glass opacity) are not specific to COVID-19 and CT positive predictors are low unless disease prevalence is high (Hope et al. 2020).

Interestingly, there was neither incidence of infection among other patients nor medical staff in this hospital during the outbreak period. This may be because $90.5 \%$ of the patients first visited the fever clinics, which are effective at triaging patients and screening suspected patients in order to reduce cross-infection (Lai et al. 2020; Zhang et al. 2020). According to the (NHC 2020), requirements the fever clinics are located in a relatively independent area 
within the medical institution from the outpatient (emergency) clinics. The setting of fever clinics is divided into a clean area, partially contaminated area and contaminated areas are equipped with entrances for the medical staff and patients; thus, making the transmission flow from the clean area to the partially contaminated area and contaminated area a one-way direction. Therefore, this finding suggests that the setting of a fever clinic is key to effectively containing the spread of airborne transmission of disease within medical institutions, especially aerosol transmission.

\section{Limitations}

Several limitations to this retrospective study need to be acknowledged. First, despite the variety of data collected, missing data remains. Second, it is difficult to conduct follow-up observations after the confirmed patients are transferred to another hospital. Third, some laboratory tests (e.g., cardiac troponin I, n-terminal brain natriuretic peptide precursor, and arterial blood gas test) were not performed in all patients, which might lead to bias of the clinical characteristics.

\section{Conclusions}

The history of high-risk area exposure in the epidemiological investigation is an important part of epidemic prevention and control in order to distinguish clinically suspected patients from confirmed patients. Multiple nucleic acid tests are the basis for diagnosing COVID-19, and the ground-glass opacity in the CT examination results is also an important indicator. The present research serves as a basis for future studies and provides additional evidence to clinicians. Given challenges in vaccine development and the surge in confirmed cases globally, more clinical research and public health management are needed to prevent the spread of the epidemic.

Acknowledgments Thanks for the manuscript guidance of Dr. Quan Jun who works in the Infectious Department of Xiangya Hospital, Central South University. And we also thank Mo Dan's help with data collection at who Infectious Department of Xiangya Hospital, Central South University. The authors thank Aimi Academic Services (www. aimieditor.com) for the English language editing and review services.

Author contributions QL and MJ contributed to collected and sorted out the data. Data analysis was performed by MJ. QL wrote the original draft preparation. SY contributed to the development of ideas and critically revision of manuscript. All authors read and approved the final version manuscript.

Funding No funds, grants, or other support were received.
Availability of data and material The datasets were analyzed during the current study available from the corresponding author on reasonable request. Anyone who is interested in the information should contact ldyse2018@csu.edu.cn.

\section{Declarations}

Conflict of interest The authors have no relevant financial or nonfinancial interests to disclose.

Ethics Approval The Ethics Committee of the review board of Xiangya Hospital of Central South University approved this study.

\section{References}

Ai T, Yang ZL, Hou HY, Zhan CN, Chen C, Lv WZ, Tao Q, Sun ZY, Xia LM (2020) Correlation of Chest CT and RT-PCR testing in Coronavirus DISEASE 2019 (COVID-19) in China: a report of 1014 cases. Radiology 296:32-40. https://doi.org/10.1148/radiol. 2020200642

Chang YX, Xu ML, Fu XH, Yin L, Wan XY, Zhang Q (2020) Investigation and analysis of false negative in throat swab nucleic acid test of COVID-19. Acad J Second Military Med Univ 41(06):592-595. https://doi.org/10.16781/j.0258-879x. 2020.06.0592

Chen T, Wu D, Chen H, Yan W, Yang D, Chen G et al (2020) Clinical characteristics of 113 deceased patients with coronavirus disease 2019: retrospective study. BMJ (online) 368:m1091. https://doi.org/10.1136/bmj.m1091

Corman VM, Landt O, Kaiser M, Molenkamp R, Meijer A, Chu DK et al (2020) Detection of 2019 novel coronavirus (2019-nCoV) by real-time RT-PCR. Eurosurveillance 25(3):2000045. https:// doi.org/10.2807/1560-7917.Es.2020.25.3.2000045

Gebhard C, Regitz-Zagrosek V, Neuhauser HK, Morgan R, Klein SL (2020) Impact of sex and gender on COVID-19 outcomes in Europe. Biol Sex Differ 11:29. https://doi.org/10.1186/s13293020-00304-9

Himoto Y, Sakata A, Kirita M, Hiroi T, Kobayashi KI, Kubo K, Kim H, Nishimoto A, Maeda C, Kawamura A, Komiya N, Umeoka S (2020) Diagnostic performance of chest CT to differentiate COVID-19 pneumonia in non-high-epidemic area in Japan. Jpn J Radiol 38:400-406. https://doi.org/10.1007/s11604-020-00958w

Hope MD, Raptis CA, Shah A, Hammer MM, Henry TS (2020) A role for CT in COVID-19? What data really tell us so far. Lancet (Lond, Engl) 395:1189-1190. https://doi.org/10.1016/s01406736(20)30728-5

Huang P, Liu T, Huang L, Liu H, Lei M, Xu W, Hu X, Chen J, Liu B (2020) Use of chest CT in combination with negative RT-PCR assay for the 2019 Novel Coronavirus but high clinical suspicion. Radiology 295:22-23. https://doi.org/10.1148/radiol. 2020200330

Kopel J, Perisetti A, Roghani A, Aziz M, Gajendran M, Goyal H (2020) Racial and gender-based differences in COVID-19. Front Public Health 8:418. https://doi.org/10.3389/fpubh.2020.00418

Lai R, Chen E, Gao W, Cheng C, Xie Q (2020) Sentinel surveillance strategies for early detection of coronavirus disease in fever clinics: experience from China. Epidemiol Infect 148:205. https://doi.org/10.1017/s0950268820001892

Li Y, Yao L, Li J, Chen L, Song Y, Cai Z, Yang C (2020a) Stability issues of RT-PCR testing of SARS-CoV-2 for hospitalized patients clinically diagnosed with COVID-19. J Med Virol 92:903-908. https://doi.org/10.1002/jmv.25786 
Li YJ, Hu YY, Zhang XD, Yu YY, Li B, Wu JG, Wu YP, Xia XP, Xu $\mathrm{J}$ (2020b) Follow-up testing of viral nucleic acid in discharged patients with moderate type of COVID-19. J ZheJiang Univ (med Sci) 49(2):270-274

Li Q, Guan X, Wu P, Wang X, Zhou L, Tong Y et al (2020c) Early transmission dynamics in Wuhan, China, of Novel Coronavirusinfected pneumonia. New Engl J Med 382:1199-1207. https:// doi.org/10.1056/NEJMoa2001316

Li WH, Xiong P, Zhao XH, Chen YF, Liu B, Liu M, Chen QC (2020d) China's strategy and experience in preventing and controlling the local spreading and epidemic of COVID-19. Shanghai J Prev Med 32(9):704-711. https://doi.org/10.19428/j. cnki.sjpm.2020.20326

Li YK, Peng S, Li LQ, Wang Q, Ping W, Zhang N, Fu XN (2020e) Clinical and transmission characteristics of Covid-19-a retrospective study of 25 cases from a single thoracic surgery department. Curr Med Sci 40:295-300. https://doi.org/10.1007/ s11596-020-2176-2

Long DR, Gombar S, Hogan CA, Greninger AL, Shah VOR, BrysonCahn C et al (2020) Occurrence and timing of subsequent SARSCoV-2 RT-PCR positivity among initially negative patients. Clin Infect Dis. https://doi.org/10.1093/cid/ciaa722

National Health Commission of the People's Republic of China (2020) Novel Coronavirus epidemic prevention and control. http://www.nhc.gov.cn. Accessed 3 Nov 2020

National Health Commission of the People's Republic of China (2020) Notation on diagnosis and treatment scheme for SARSCoV-2 of Chinese (eighth edition). http://www.nhc.gov.cn. Accessed 12 Nov 2020
National Health Commission of the People's Republic of China (2020) Notice on issuance of Technical Guidelines for Construction Equipment of Fever Clinics (Trail). http://www.nhc. gov.cn. Accessed 15 Sept 2020

Pang J, Wang MX, Ang IYH, Tan SHX, Lewis RF, Chen JI et al (2020) Potential rapid diagnostics, vaccine and therapeutics for 2019 Novel Coronavirus (2019-nCoV): a systematic review. J Clin Med 9:623. https://doi.org/10.3390/jcm9030623

WHO (2020) WHO director-general's remarks at the media briefing on 2019-nCoV on 11 February 2020. https://www.who.int. Accessed 3 No 2020

WHO (2020) Coronavirus disease (COVID-19) outbreak. https:// www.who.int. Accessed 3 Nov 2020

WHO (2020) WHO Coronavirus disease (COVID-19) dashboard. https://www.who.int. Accessed 3 Nov 2020

Wiersinga WJ, Rhodes A, Cheng AC, Peacock SJ, Prescott HC (2020) Pathophysiology, transmission, diagnosis, and treatment of Coronavirus disease 2019 (COVID-19): a review. JAMA 324:782-793. https://doi.org/10.1001/jama.2020.12839

Zhang J, Zhou L, Yang Y, Peng W, Wang W, Chen X (2020) Therapeutic and triage strategies for 2019 novel coronavirus disease in fever clinics. Lancet Resp Med 8:11-12. https://doi. org/10.1016/s2213-2600(20)30071-0

Zhou F, Yu T, Du R, Fan G, Liu Y, Liu Z et al (2020) Clinical course and risk factors for mortality of adult inpatients with COVID-19 in Wuhan, China: a retrospective cohort study. Lancet (Lond, Engl) 395:1054-1062. https://doi.org/10.1016/s01406736(20)30566-3 